\title{
Analysis of the Bases of Power of Key Players in the Industry of Novel Psychoactive Substances
}

\author{
Ahmed Al-Imam ${ }^{1,2} \&$ Ban A. AbdulMajeed ${ }^{3}$ \\ ${ }^{1}$ Department of Postgraduate Medicine, School of Life and Medical Sciences, University of Hertfordshire, United \\ Kingdom \\ ${ }^{2}$ Department of Anatomy and Cellular Biology, College of Medicine, University of Baghdad, Iraq \\ ${ }^{3}$ Department of Pathology and Forensic Medicine, College of Medicine, Al-Nahrain University, Iraq \\ Correspondence: Dr Ahmed Al-Imam, House 18/5, Al-Akhtal Street, District 318, Al-Adhamyia, 10053, Baghdad, \\ Iraq. E-mail: tesla1452@gmail.com; a.m.al-imam@herts.ac.uk
}

Received: July 25, 2017 Accepted: August 17, 2017 Online Published: September 18, 2017

doi:10.5539/gjhs.v9n11p14 URL: https://doi.org/10.5539/gjhs.v9n11p14

\begin{abstract}
Background: The study of novel psychoactive substances (NPS) should be at the intersect of neuroscience, psychology, social science, data science, information and communication technology, policy-making, and legislation. The amalgamation of social science should be widely implemented; the concept of the individual basis of power (authority) has been applied in this study; the aim was to quantify the magnitude of authority for the major players in connection with the NPS industry.

Materials and Methods: Data were collected for NPS researchers and e-vendors. Concerning the NPS scientists, fifty researchers were randomly picked using a random number generator. For each researcher; a power score was calculated; the power scoring is representative for the individual basis of power. There will be a kindred analysis for e-vendors on the darknet; the power scoring will rely on; e-vendor level, trust level, duration of membership in the e-market (vendor's antiquity), number of positive and negative feedbacks from e-customers, number of sold substances, number of subscribers, and e-vendor's scoring on Grams search engine.

Results: Unfortunately, the summative power scores of NPS protagonists were higher than those who oppose and regulate the NPS phenomenon. Terrorist organisations were found to possess the highest power scores due to the additional use of illegal tactics. Power scoring for NPS researchers was highest in Europe, particularly the in the UK and Italy. On the other hand, e-vendors' power scoring was highest for the AlphaBay e-market of the darknet.

Conclusion: Principles of social science and psychology should be integrated into the collaborative efforts of NPS researchers. This study proposes a novel method to assess the authority of NPS-related personnel existing within the virtual space of the web; its applications are not limited to NPS researchers and e-vendors but can also be applicable for; e-markets, e-customers and (ab)users, and policy makers.
\end{abstract}

Keywords: Novel Psychoactive Substances, NPS, power, psychoanalysis, social sciences, research personnel, electronic commerce, vendors, Surface Web, Deep Web, Darknet, Scoring System

\section{Background}

The flourishing "industry" of novel psychoactive substances (NPS) and its collateral e-phenomena must have a rational explanation; these are already accounted for by the parallel logarithmic evolution of information and communication technologies (Al-Imam et al., 2016; Al-Imam et al., 2017; Helander et al., 2013). However, many experts doubt that this is not the full truth; the theories of social science can also be applied with an aim to provide a plausible explanation (Moore et al., 2013; Wood et al., 2012). Social science has been very successful in explaining unique occurrences including; economics, game theory, political events, polls, and even in relation to the theory of Darwinian's evolution (Campbell, 1975; Frey 1999; Morrow 1994; Plides 2001; Shubik 1984). Hence, the integration of principles of social science is complementary and innovative; one of the critically acclaimed principles of social science is the individual basis of power (Bourdieu, 1994; Katz and Khan, 1978; Wrong, 2017).

The individual basis of power (authority) includes three main components; personal, structural, and cognitive (University of Michigan, 2017; Wrong, 2017). The same basis of power can be implemented to explain the unbalance between antagonists of the NPS phenomenon (anti-NPS) versus its protagonists and enthusiasts 
(pro-NPS) (Al-Imam et al., 2017; Dargan \& Wood, 2013). NPS antagonists include NPS investigators and researchers, legislators and policy makers, and regulating bodies; the regulating bodies are represented by the United Nations Office on Drugs and Crime (UNODC), World Health Organization (WHO), the United States Food and Drug Administration (FDA), World Anti-Doping Agency (WADA), the European Monitoring Centre for Drugs and Drug Addiction (EMCDDA), Novel psychoactive treatment: UK network (NEPTUNE), and others (David, 2013; EMCDDA, 2016, Mackey and Liang, 2013). On the other hand, NPS protagonists are not limited to; vendors and e-vendors, e-markets on both divisions of the web (surface and deep web), NPS chemists, in addition to terrorists. Terrorist organisations have been recently incriminated in using NPS stimulants including phenethylamines and amphetamines, for instance, the use of captagon (fenethylline) in the terror attacks across Europe in 2015 and 2016 (Al-Imam, 2017; Al-Imam et al., 2017; Ekici \& Ozbay, 2013; Ganor \& Halperin, 2013; Kravitz \& Nichols, 2016; Mackey \& Liang, 2013; Ward \& Mabrey, 2013).

There are dozens of e-markets of darknet on the deep web; the most popular are AlphaBay, Agora, Nucleus, Valhalla, and HANSA (Broséus et al., 2016; Celestini et al., 2017; Grisham et al., 2016; Wehinge, 2011). Those e-markets and their e-vendors can also be analysed using models of social science. The aim of these analyses is to infer the primary drivers of the NPS e-commerce and the extent of their power. The objective of these scoring and inferences is to deduce, based on mathematical quantification, the power (authority hierarchy) within the mega market of this ambiguous industry. The inclusion of concepts of social science is a different cornerstone that was not considered seriously to counteract the extraordinary evolution of the NPS. The social science potential is critical and can be deployed in parallel with data mining techniques and knowledge discovery in databases for effective control of the NPS hypermarket (Fayyad et al., 1996; Jelen \& Laexander, 2006; O'Leary, 2004). Those principles will also attempt to explain the lack of presentation, e-vendors, and researchers from the developing regions of the world including the Middle East.

\section{Materials and Methods}

This study has been ethically approved by the institutional review board (IRB) of the College of Medicine at the University of Baghdad (IRB meeting number 8 , on the $20^{\text {th }}$ of December 2016). The basis of power will be analysed in relation to the key players within the NPS "industry"; these players will be divided into; NPS protagonists (pro-NPS) and NPS antagonists (anti-NPS). Pro-NPS include vendors, e-vendors on surface web, e-vendors on the deep web, NPS (ab)users, chemists, and terrorists. All those agents (key players) interact with each other within the NPS markets, e-markets, legislation and policy-making, and even in connection to terrorism and counter-terrorism. The individual basis of power are divided into three broad categories; structural, personal, and cognitive (University of Michigan, 2017; Spekman, 1979). Each of these has sub-components; personal power is based on expertise, information, and referent power; cognitive power relies on priming and beliefs; structural power relies on legitimate power, reward, and coercion. The details of these belong to the realm of social science. However, the scoring of power for each of the key players will be based on these power-determining parameters.

The basis of power for NPS researcher is to be more thoroughly explored; fifty scholars were chosen at random, using a random number generator application; researchers were selected from an established database of 587 entries (researchers). The database was created via consulting PubMed/Medline; PubMed has been systematically searched for publications specific to the discipline of NPS. The aim of the search was to establish a database which is representative of the majority of publications in NPS research globally. Specific keywords were used; novel psychoactive substances (1), novel psychoactive substance* (1), new psychoactive substance (3), new psychoactive substance* (4), and (novel psychoactive substance*) OR (new psychoactive substance*) (5). The systematic search took place in January and February 2017. Furthermore, no filters were used, in an attempt to avoid biases in relation to geographic location, researchers, date of publication, or research institutions.

This selection process of NPS researchers led to the creation of the $2^{\text {nd }}$ database with 50 entries; each entry (NPS researcher) had 14 determinant parameters including the researcher name (1), academic title or status (2), number of indexed publication on PubMed/Medline (3), ResearchGate (RG) score (4), number of research items on RG (5), number of citations on RG (7), number of followers on RG (8), percentile RG scoring (9), h-index score on RG (10), direct and indirect reach on RG $(11,12)$, in addition to the analyses of body language and speech which are based on Youtube videos $(13,14)$. Speech analyses were done in relation to the Han's Rosling effective range of speech; the speech for NPS researchers found on Youtube, and other online platforms were analyzed regarding; the number of words per minute, fluency and coherence of expression, in addition to the collateral body language (University of Michigan, 2017). To summarise, each researcher had parametric data gathered from; the surface web, research institute, PubMed, ResearchGate, and Youtube (Burgess et al., 2013; Martín-Martín A. et al., 2016; US National Library of Medicine National Institutes of Health. PubMed, 2017). These data were corrected and numerically scored in ascending order; these scores were later treated mathematically to calculate a power score for each researcher. The power score is expressive to the authority for each researcher. 
Another scoring system, a security scoring, was also established for each of the 50 researchers. Security score was calculated mathematically as a representative of another 14 parameters; scholar title (1), facial features (2), number of publications (3), his/her research Institute (4), country (5), previous research institute(s) names (6), academic backgrounds and expertise (7), his/her network on PubMed (8), networking on RG (9), availability of Youtube videos (10), email and phone number $(11,12)$, social status (13), and funding bodies (14). Hence, it can be deduced that the security score may also be considered as a determinant of the power and authority. However, it's fundamentally different from power score; security score is a measure (index) of how much data on the web, can be easily retrieved for a particular NPS researcher. In other words, the availability of redundant information on an individual researcher can be considered a weakness. Hence, the stronger a researcher, the more he (or she) should be anonymous on the web. To summarise, each of the power score and the security score represents an index on the basis of power; each scoring method approaches the power analysis from a unique perspective.

Power scores were also be established for e-vendors on the deep web, specifically on the e-markets of the darknet. Analogous scores were also generated for e-markets on the darknet, including three of the famous e-markets on darknet; AlphaBay, Valhalla, and Hansa. Generally speaking, power scores for e-vendors will be based on analogous parameters, including vendor level, trust level, duration of membership (vendor's antiquity), number of positive and negative feedbacks from e-customers, number of sold orders, number of subscribers, and e-vendor scoring on Grams search engine (Agichtein et al., 2001; Nakov and Hearst, 2005). All these parameters generated highly accurate power scores for e-vendors; this was followed by performing statistical inferences and special correlations. Statistical tests included linear regression and Student's t-test (paired and independent). Alpha $(\alpha)$ value of 0.05 and a confidence interval of $95 \%(95 \% \mathrm{CI})$ has been considered as the cutoff margin for statistical significance; these analyses were also geographically mapped.

\section{Results and Discussion}

The calculation of power scoring (Figure 1 and 2) revealed that the summative power score of Pro-NPS (48+) was much higher than that of Anti-NPS (21+). This may partially explain why the NPS phenomenon, particularly its e-trade and e-commerce, is spreading at an exponential rate outpacing the efforts of NPS antagonists (anti-NPS). However, these raw scores are not entirely accurate; some component of the basis of power cannot be estimated or quantified; these components could be anonymous. One of these is the cognitive foundation of the power of key players on the e-markets of the deep web. The anonymity of the deep web is the reason behind the lack of accuracy of authority scoring calculations (Conrad 2002; Mayer 2009; Phelps and Watt 2014, Van Hout et al., 2014). Pro-NPS seems to be ahead (more powerful) especially when it comes to terrorists; they can use illegal methods leading to an illegitimate power; including drug trafficking (trade and e-trade), unlawful coercion and punishment, altogether with the lack of sense of morality, and the act of terror itself.

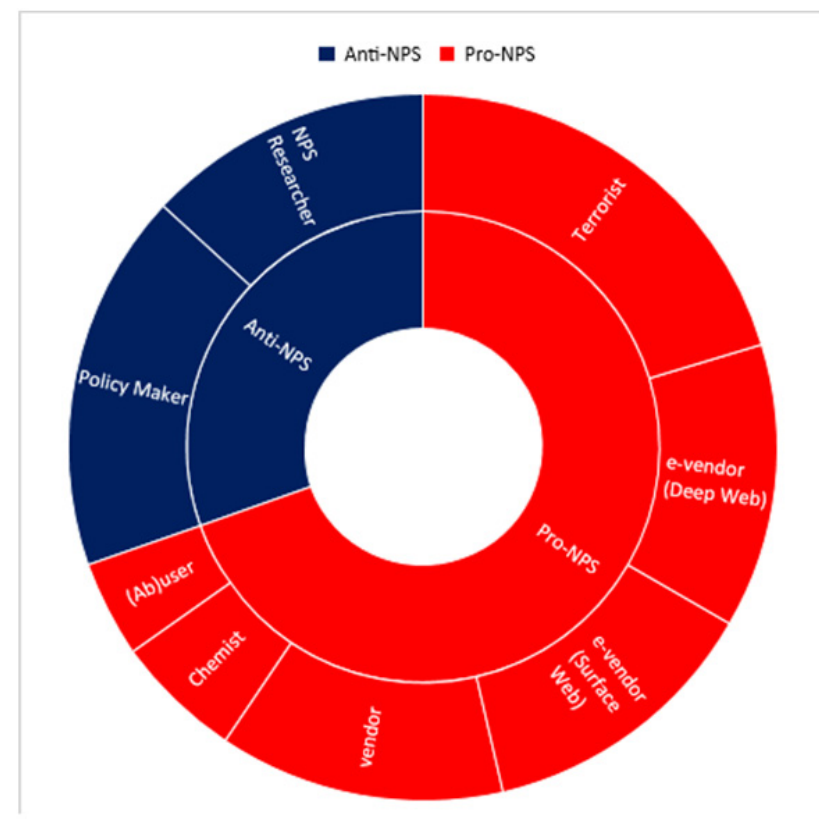

Figure 1. Components of Basis of Power of Pro-NPS vs Anti-NPS: Donut Presentation

${ }^{\Omega}$ Anti-NPS agents are labelled as blue 


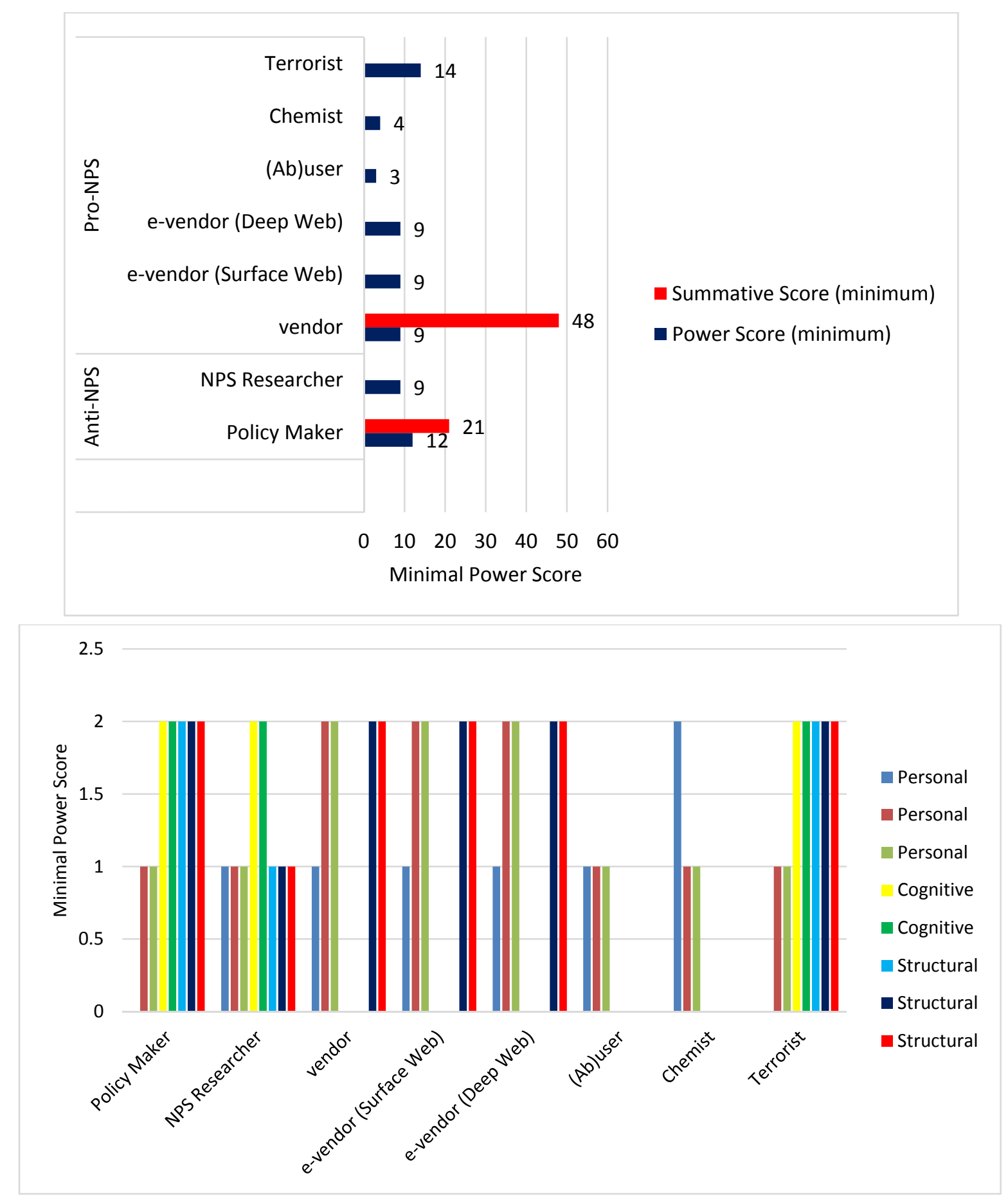

Figure 2. The Individual and Summative Scoring of Power: Pro-NPS vs Anti-NPS

The power scores for NPS researchers were diverse (Figure 3). However, there were no exceptional cases (statistical outliers) for each of the power score and the Security score. Authority and security scores were found to run in parallel with each other; their trends go up and down simultaneously. Hence, a positive correlation was hypothesised in between the two, and a linear regression was plotted accordingly; truly, there was a positive relationship $\left(R^{2}\right.$ score $\left.=0.560\right)$. Consequently, it can be inferred that as the power of an NPS researcher increases, more data will be available on him (her) on the web, and his (her) corresponding anonymity on the internet will be varying accordingly. The number of publications indexed on PubMed was adopted as an indicator for the research output, and based on the Q-Q plot of research output, a cutoff limit of 40 academic publications per researcher was 
considered as the demarking point between low output versus high output researchers. Accordingly, an intergroup analysis (low versus high output, with 25 researchers per group) was deployed; there was a significant difference for power score ( 8.07 versus 16.22 , $p$-value $=0.0001)$ and security score $(9.48$ versus $11.52, p=0.0006)$ in between the two groups. Therefore, it can be inferred that both of power and security scores were significantly higher for high-output researchers. However, their anonymity on the web was lower than those of low research output.
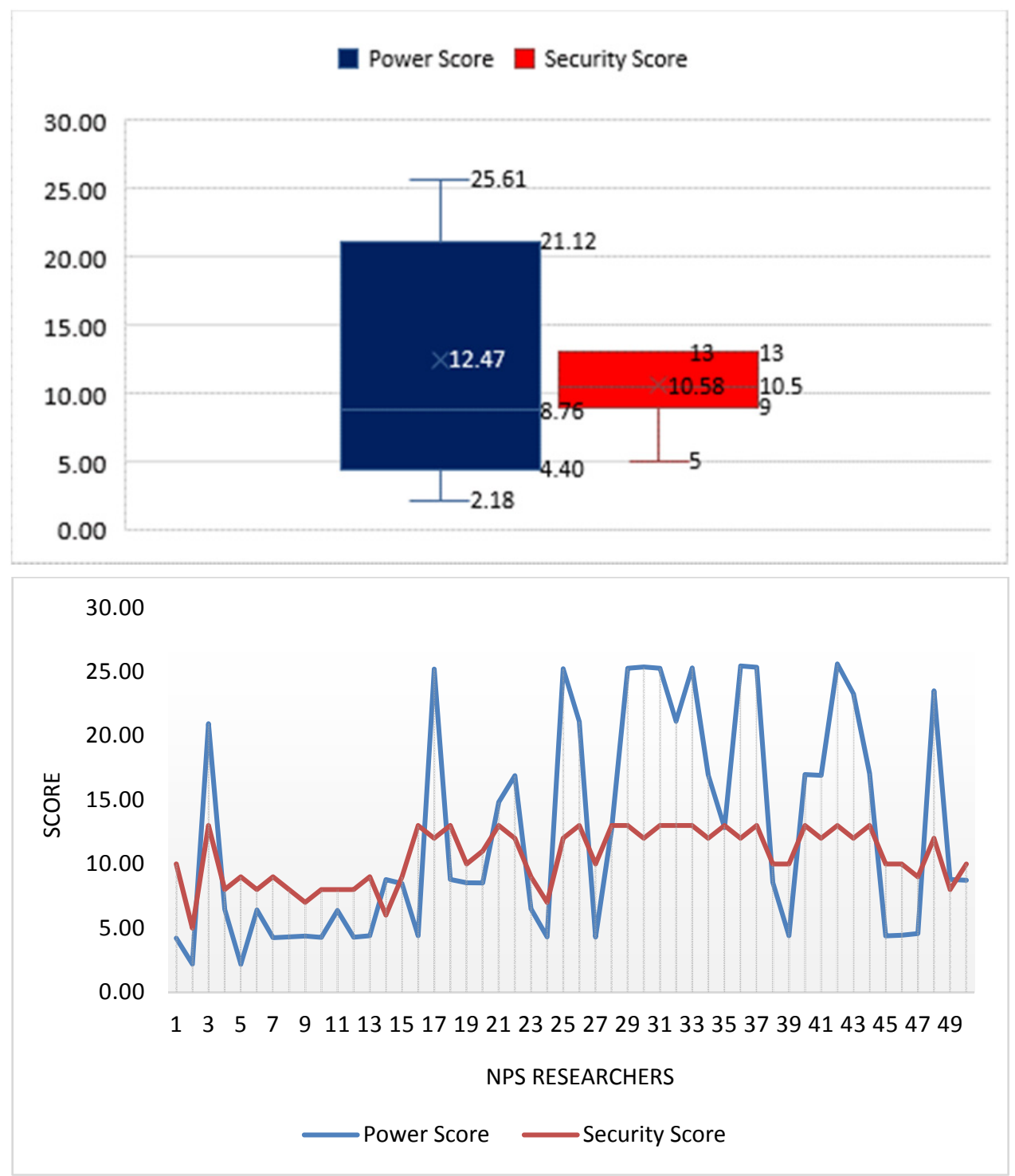

Figure 3. Power Score and Security Score: Boxplot Presentation (above), Comparative Line Graph (below)

In relation to security scores, there were no statistical outliers; linear regression revealed some degree of positive correlation $\left(R^{2}\right.$ score $\left.=0.029\right)$ between the number of publications (PubMed/Medline) and Security scores. The Security scores for NPS researchers $(n=50)$ were further analyzed by geographic location; There was significant difference between summative scores for the UK vs. Australia ( $p$-value $=0.029)$, Italy vs. Portugal (0.023), Italy vs. Australia (0.023), Germany vs. the UK (0.001), Germany vs. Italy $(0.027)$, Germany vs. Portugal $(0.001)$, Portugal vs. Australia (0.019), US vs. UK (0.027), and US vs. Portugal (0.017). To be concluded, NPS researchers from UK, US, Germany had the highest research output, higher power scores and Security scores, and less anonymity on the web. A more integrated analysis (Figure 4 and 5) by continents (inter-continental) showed that the average security scores were higher in Europe (10.8) and North America (11) than in Australasia (9.8) and Asia (9.3). It is also to be noticed that the random selection process yielded no researchers $(0 \%)$ from the Middle East. 


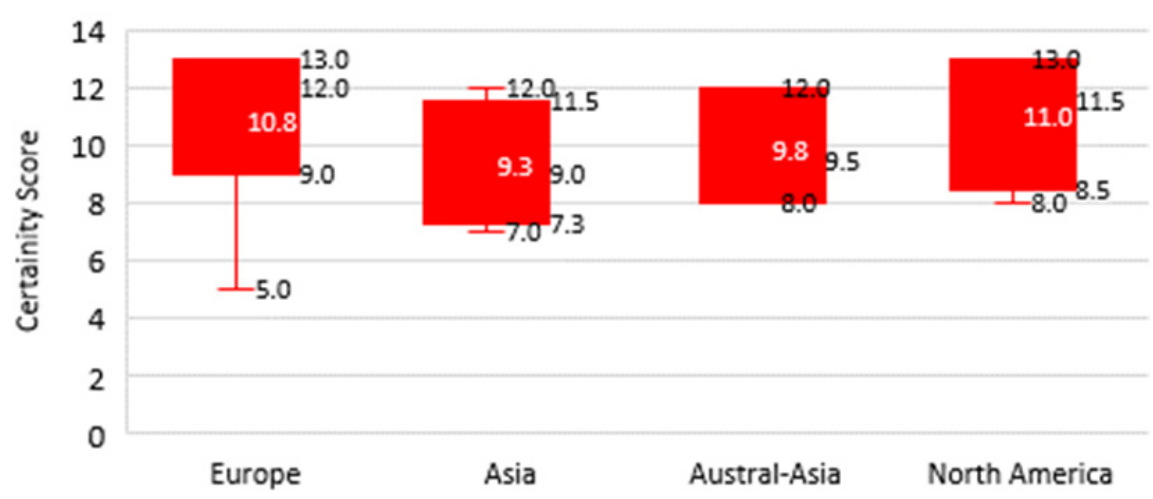

Figure 4. Security Scores by Continents

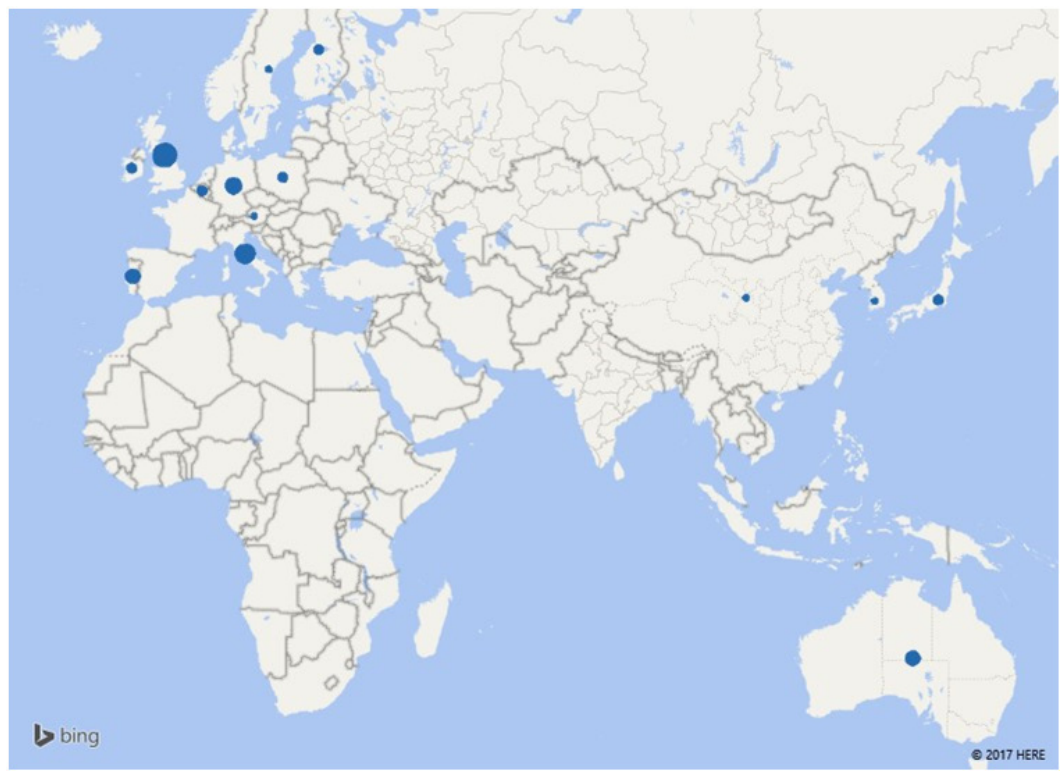

Figure 5. Geographical Presentation: Continental Security Scoring in Europe, Asia, and Australasia

AlphaBay e-market analysis was based on an internet snapshot taken on the $7^{\text {th }}$ of February 2017. The analysis deduced that the psychoactive substances (Figure 6) were; Benzodiazepines (14646, 8\%), Cannabis, Hashish, and cannabinoids (64903, 33\%), Dissociatives (4303, 2\%), Ecstasy and empathogens (30059, 15\%), Opioids (16849, 9\%), Paraphernalia (892, <1\%), Prescription medications (8720, 4\%), Psychedelics (13935, 7\%), Stimulants (32494, 17\%), and other miscellaneous substances. A parallel snapshot was taken for e-vendors on AlphaBay, e-vendors $(\mathrm{n}=40)$ were randomly picked using a random number generator. Each was scored for power; the scoring was based on; vendor level, trust level, duration of membership, and the percentage of positive feedbacks from e-customers. Power score and determinants of power score were plotted, and there were two phenomenal (outliers) e-vendors; these e-vendors were known by the usernames; FrankMatthews and GreenLeafLabs, both e-vendors shipped their substances from Europe. Linear regression showed a linear correlation of e-vendor powers score with; e-vendor's antiquity $\left(R^{2}\right.$ score $\left.=0.302\right)$, and a stronger correlation with trust level $(0.812)$. There was also a positive linear correlation between e-vendor's antiquity and his (her) trust level (0.177). It is to be inferred that trust level for each e-vendor is the most critical determinant of power for a specific e-vendor on AlphaBay. 


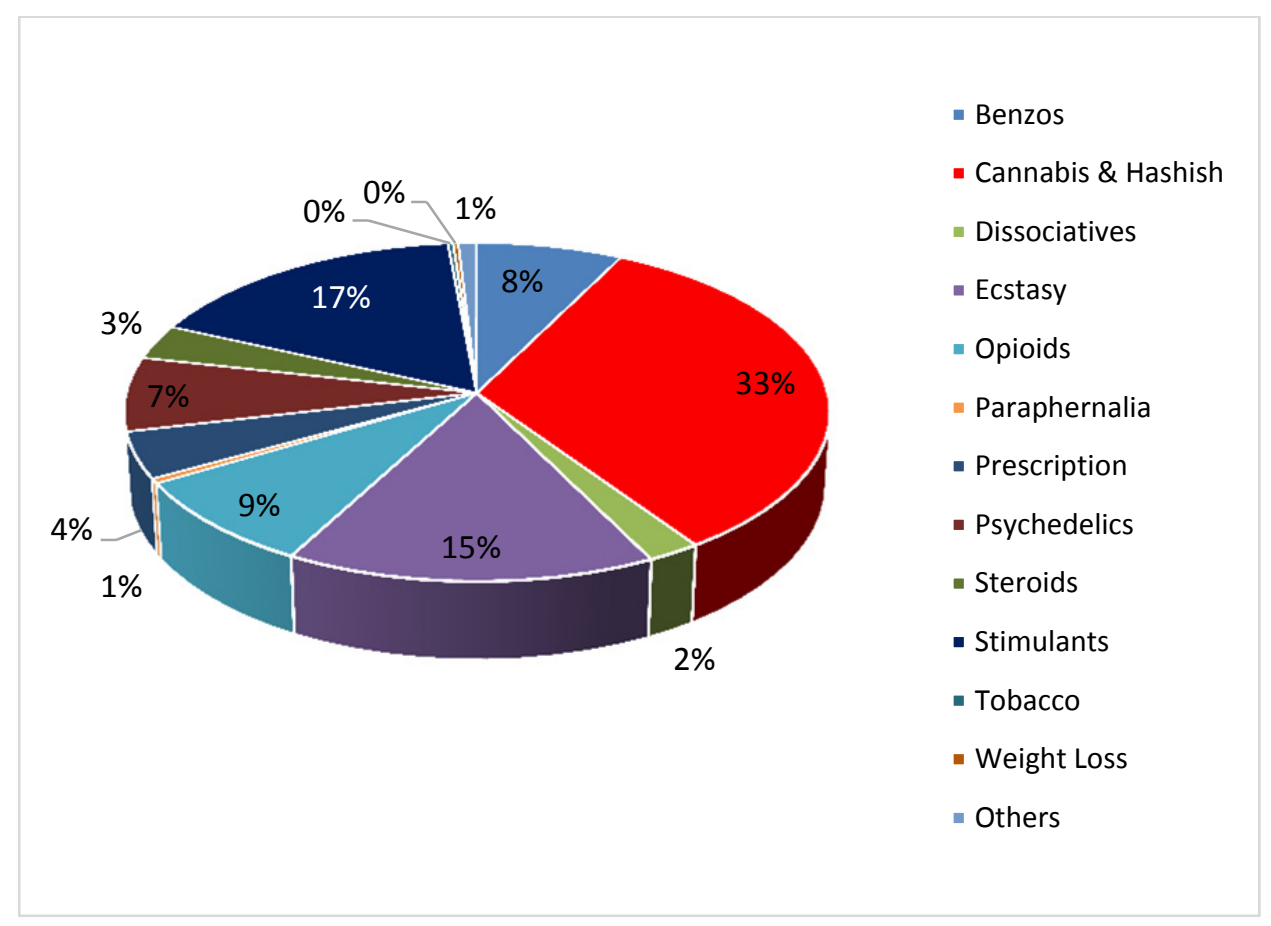

Figure 6. Substances Advertised on AlphaBay e-market

Valhalla e-market was analysed in a similar fashion to AlphaBay (Figure 7); the percentile distribution of the number of advertised substances was comparable to those on AlphaBay; Cannabis and Hashish, stimulants, empathogens, and psychedelics were at the lead. Forty e-vendors were randomly picked $(n=40)$; one statistical outlier was detected, the e-vendor username was DCdutchconnectionUK, his (her) shipping countries included the UK and Netherlands. Power score analysis for Valhalla e-vendors was based strictly on the number of positive and negative feedbacks from e-customers. Summative power scoring was calculated for geographic location (shipping country of e-vendors); UK, Finland, US, and the Netherlands were at the lead (Figure 8); other countries included Germany, Poland, Norway, Spain, India, and China; no countries from the Middle East appeared. The top three shipping countries (UK, Finland, and the US) were tested using the independent t-test. There was a statistically significant difference of UK over both; US (40 vs 16, $p$-value $=0.060)$ and Finland (40 vs 20, p $=0.030$ ), while no difference was detected between US and Finland (16 vs 20, $\mathrm{p}=0.260$ ). It is to be inferred that e-vendors from the UK possessed the highest power score. The percentile distribution of the advertised psychoactive substances, traditional and novel, was comparable on AlphaBay and Valhalla. Additionally, power scoring for both e-markets seems to run also in parallel (Figure 9). 


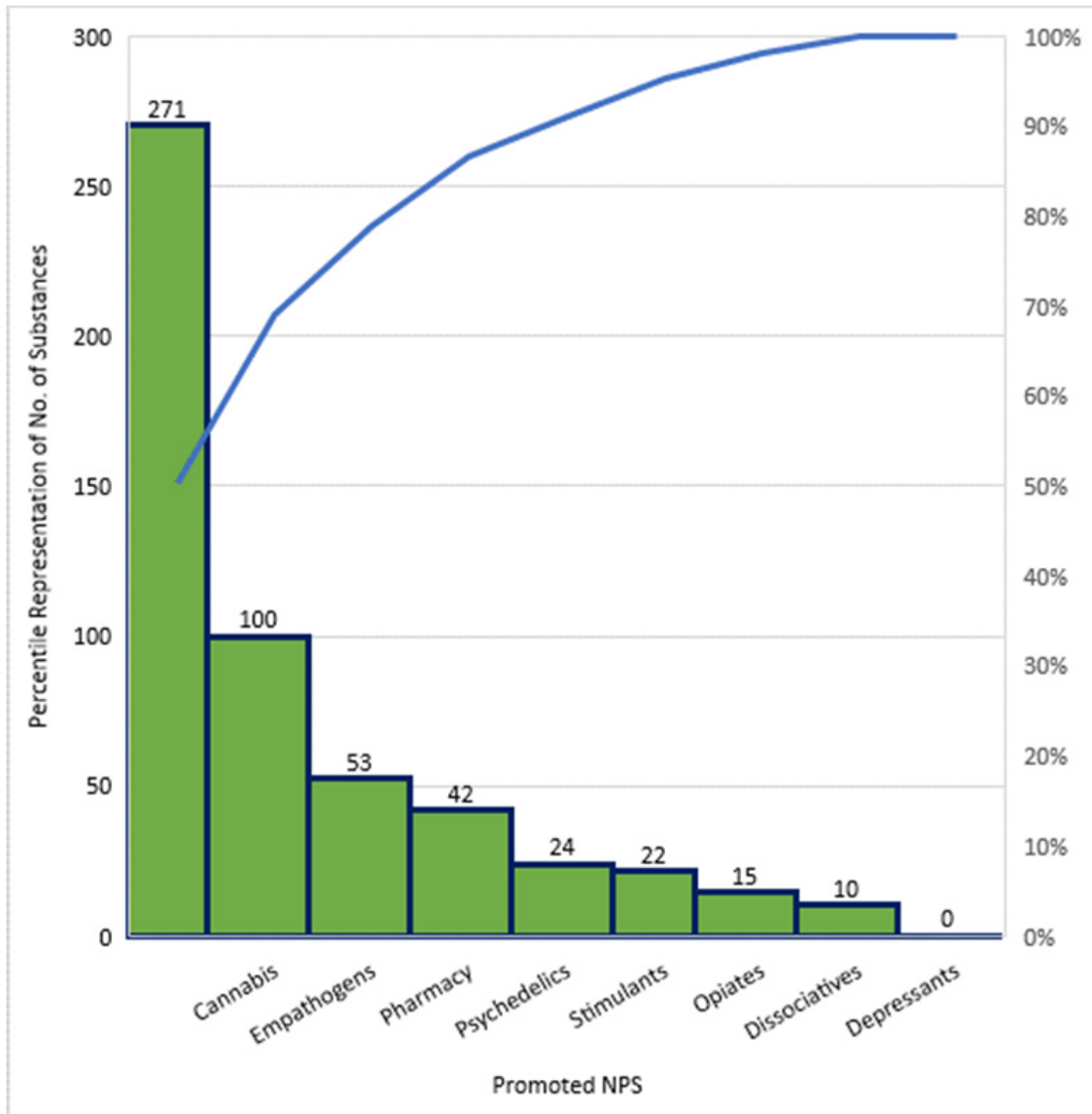

Figure 7. Substances Advertised by on Valhalla e-market

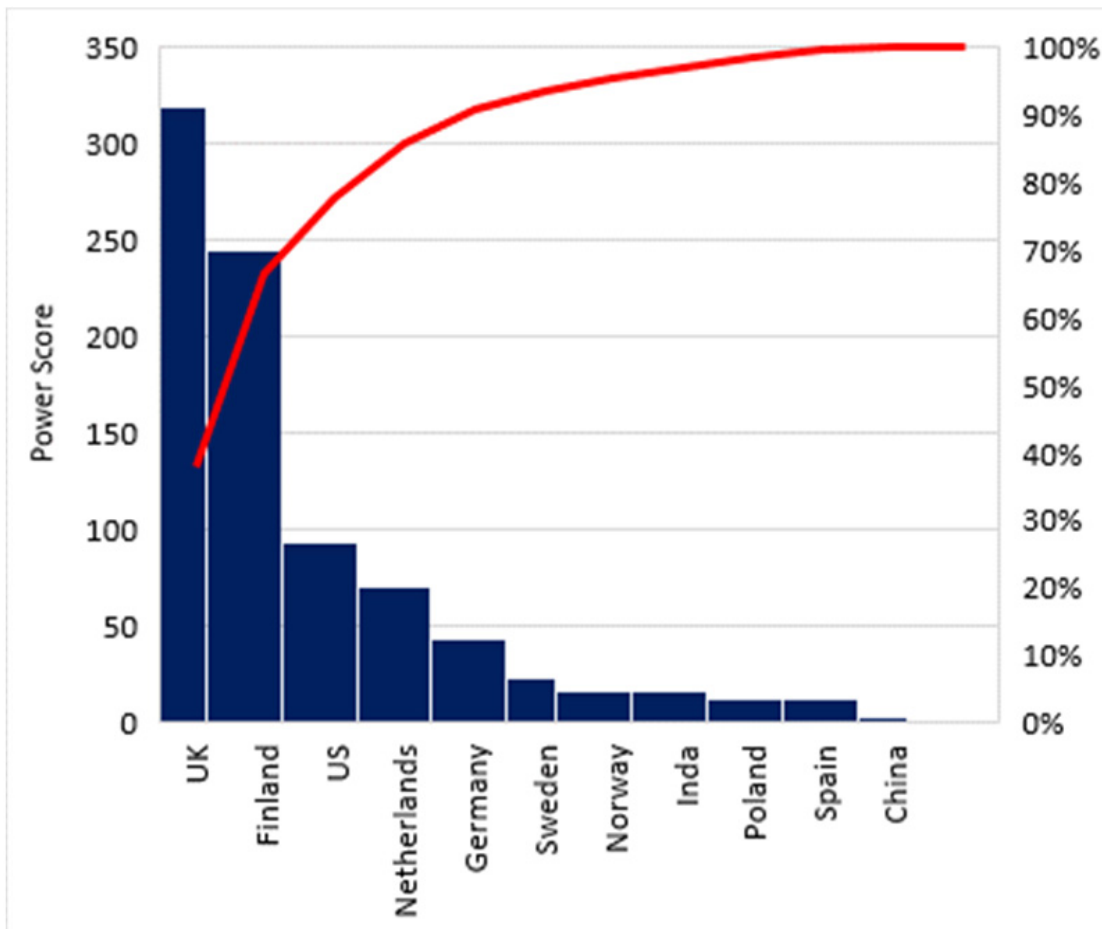

Figure 8. Summative Power Score of e-vendors on Valhalla 


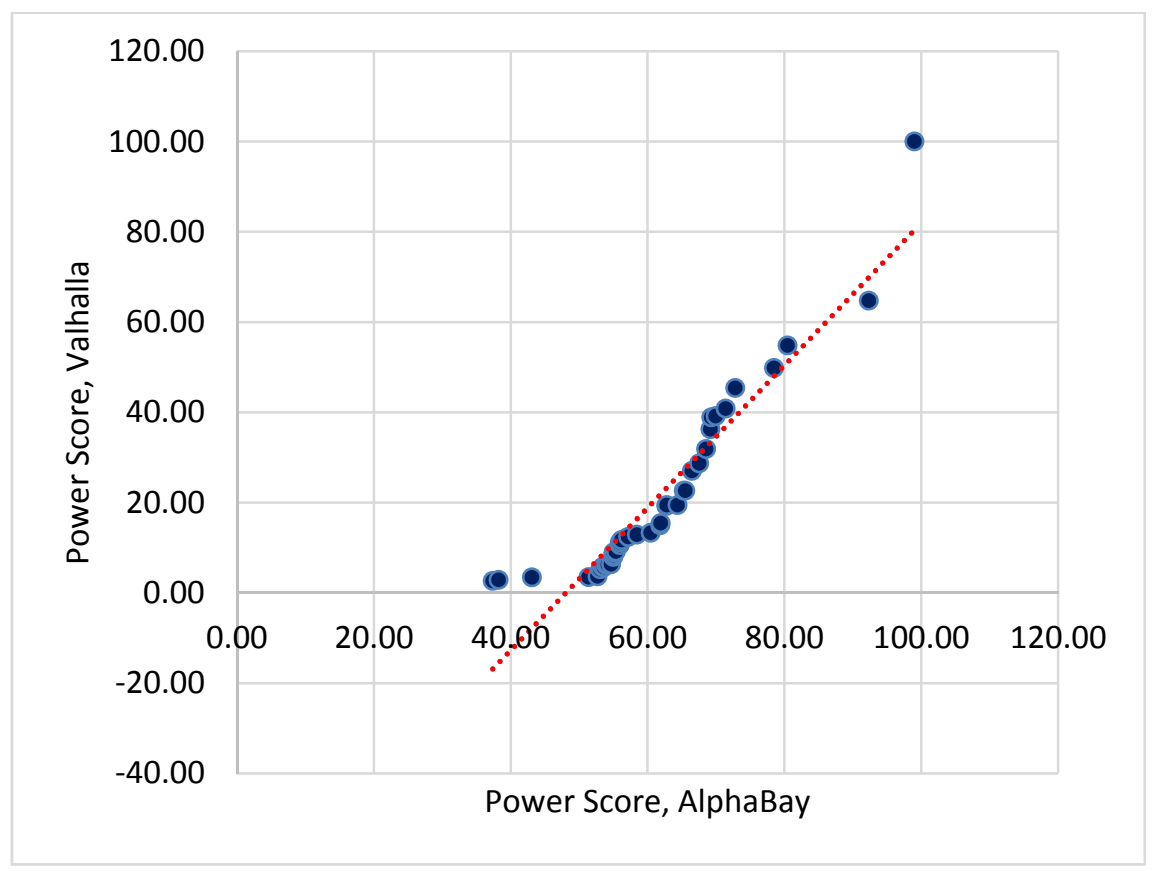

Figure 9. Power Score Correlation: AlphaBay vs Valhalla

On the $3^{\text {rd }}$ e-market, HANSA, the type and percentile contribution of psychoactive substances were also in harmony with the results from each of AlphaBay and Valhalla (Figure 10). Cannabis and cannabinoids were always the most advertised category of substances in all three e-markets; Cannabis and cannabimimetic represented almost one-third of the promoted substances in each of the three e-markets. Moreover, cannabis and cannabinoids represented an obvious statistical outlier; no other outliers were detected. The other most popular NPS were stimulants, empathogens, and psychedelics. Power scores for e-vendors $(n=40)$ were based on a snapshot taken on the $8^{\text {th }}$ of February 2017; power scoring was based on; trust and vendor level, positive and negative feedbacks, e-vendor's antiquity, the number of orders, and the number of subscribers. Power scoring of the e-vendors revealed the existence of two outliers; Saint_Symbiosis (UK) and empathogens (Canada). Based on visual data (Figure 11), it appears that the number of orders and the number of subscribers for e-vendors (HANSA) ran in parallel with each other (strong positive linear relationship), in contrary to the antiquity of e-vendors. Summative power score for shipping country of e-vendors has clearly shown that the top shipping countries were; the US (33\%), Netherlands (24\%), Canada (14\%), and the UK (13\%) (Figure 12). Other countries included Germany, Spain, Czech Republic, Philipines, and China. On the other hand, the highest number of orders and subscribers from Europe was found to originate from the Netherlands, UK, and Germany. However, the average power score for e-vendors in the US and Netherlands was not significantly different $(34.42 \%$ vs $28 \%$, $p$-value $=0.226)$. The strongest linear correlation for e-vendor power score was with; the number of orders $\left(R^{2}\right.$ score $=0.724)$, and the e-vendor level $(0.715)$, while the weakest was with e-vendor antiquity (0.143). It can be concluded that the patterns of correlation of power scoring and geographic mapping of HANSA are distinct.

Finally, though the sample of e-vendors (on AlphaBay) and NPS researchers (chosen from PubMed/Medline database) were not homogenous, corrective calculation (homogenization) was performed; the aim was to infer if the power score is significantly higher in one group. Independent t-testing confirmed that AlphaBay e-vendors possessed higher authority scoring than researchers of NPS (61.52 vs 48.68, $p$-value $=0.01)$. Hence, the NPS researchers are still lagging behind. 


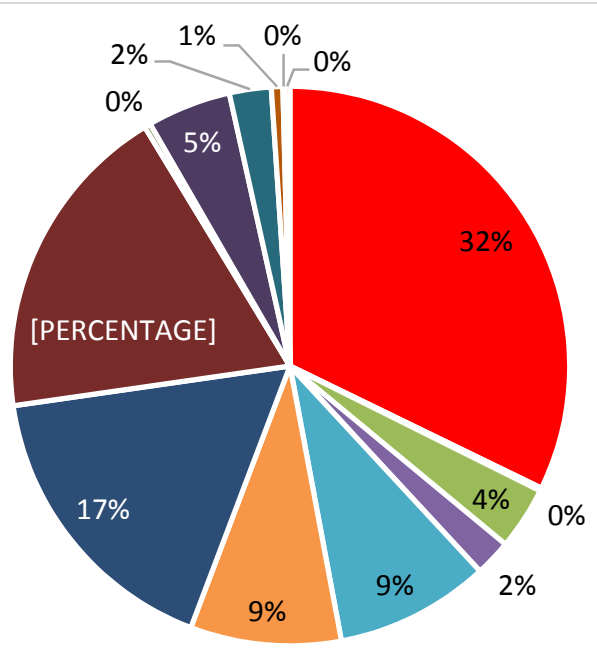

$$
\begin{aligned}
& \text { - Cannabis } \\
& \text { - Tobacco } \\
& \text { - Opioids } \\
& \text { - Steroids } \\
& \text { - Psychedelics } \\
& \text { - Prescription } \\
& \text { - Stimulants } \\
& \text { - Ecstasy } \\
& \text { - Weight Loss } \\
& \text { - Benzos } \\
& \text { - Dissociatives }
\end{aligned}
$$

Figure 10. Substances Advertised on HANSA e-market

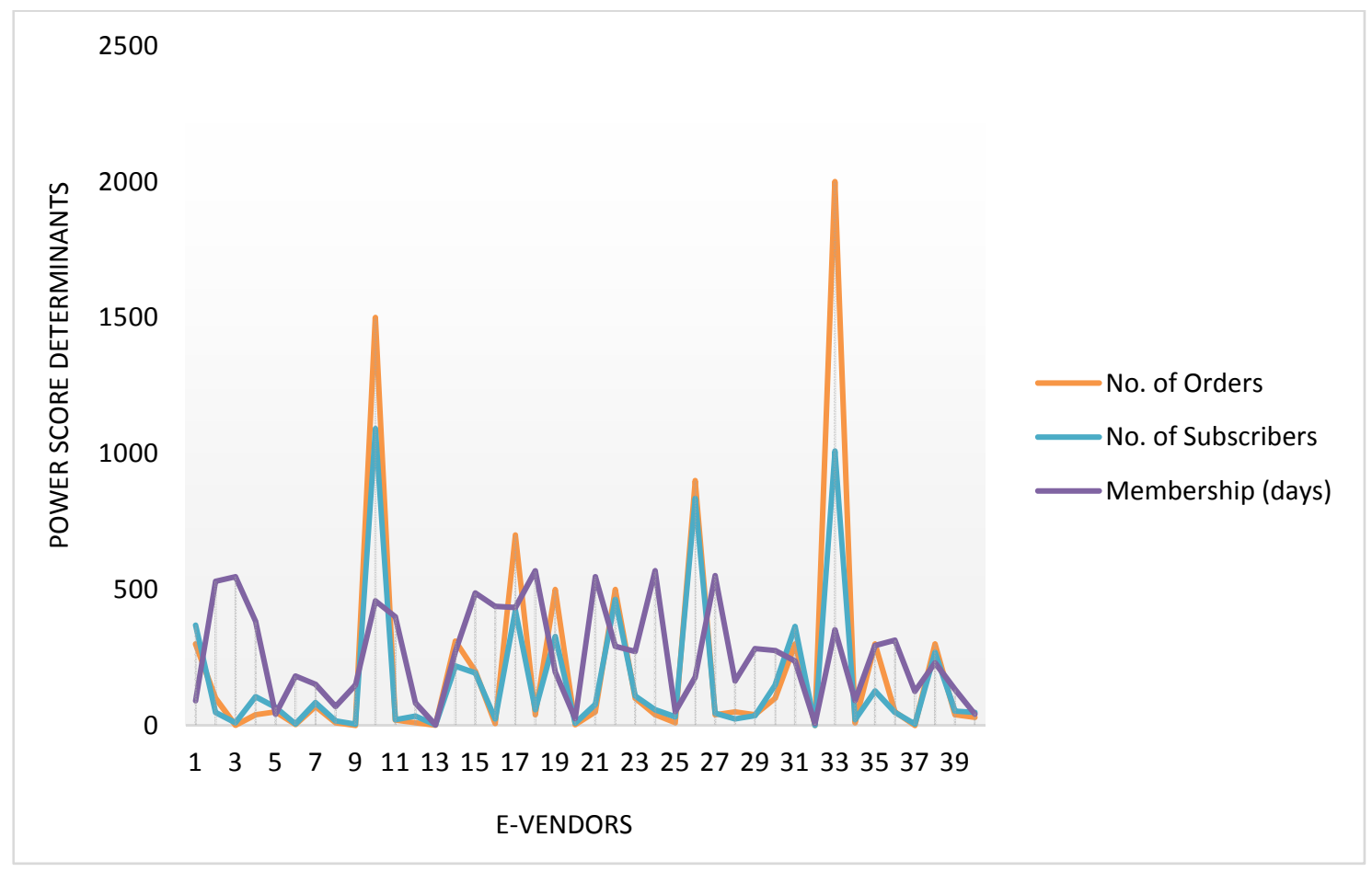

Figure 11. Determinants of Power Score for e-vendors on HANSA 

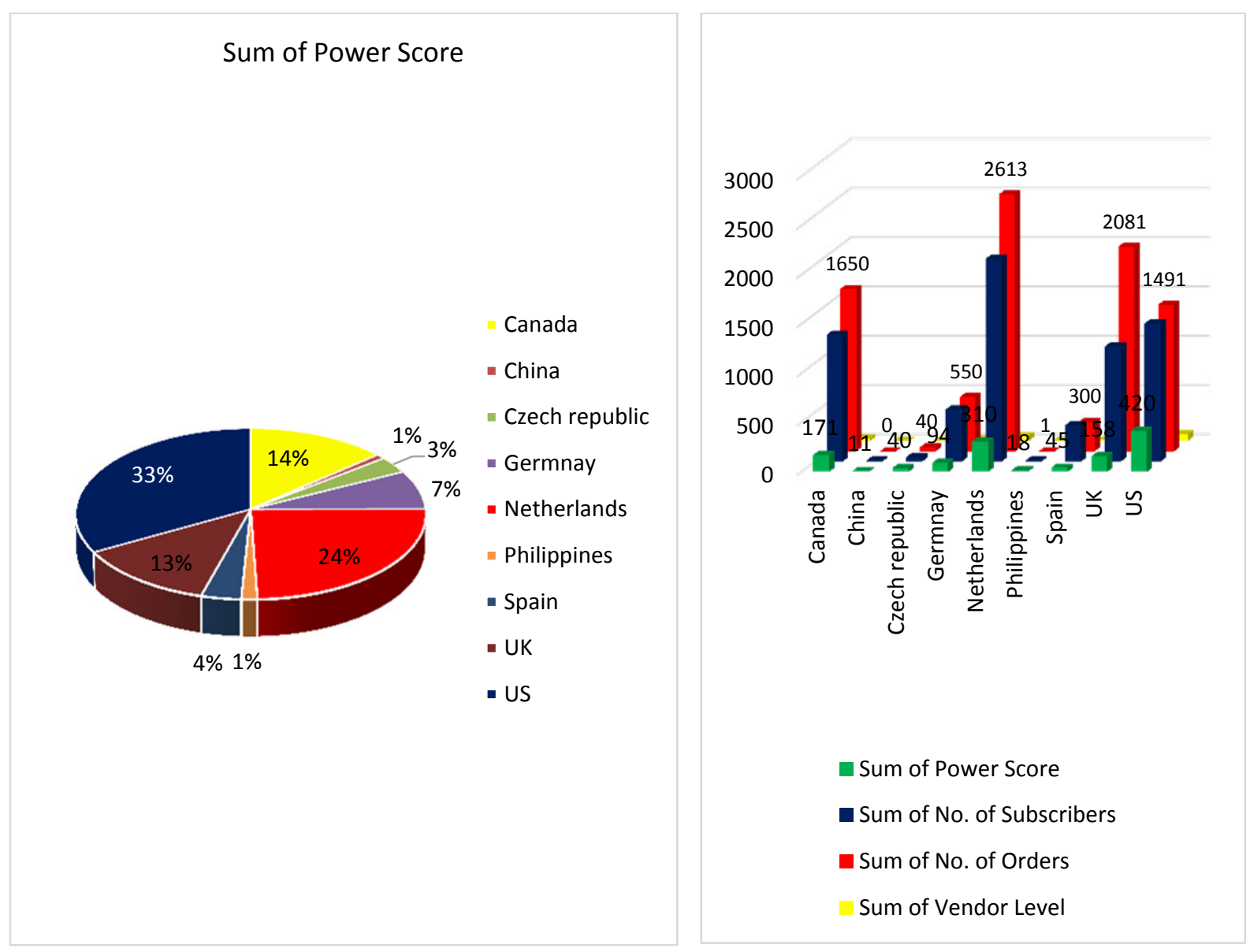

Figure 12. Top Shipping Countries: HANSA e-market

\section{Conclusion}

The principles of social science are indispensable and complementary for a holistic explanation of the NPS phenomenon, its rapid growth, and the inequitable balance between NPS protagonists and NPS antagonists. This study has proposed a novel method for quantifying the extent and hierarchy of authority for the main players within the NPS industry and its collateral e-phenomena. One limitation of this analysis is that it did not explore the basis of the power of whole units, including; NPS regulating bodies or terrorist organisations. However, the same principles of social science can also be applied in future studies. Similar ventures of social science in connection with the discipline of NPS were never explored before in the published literature. The analysis of the individual basis of power has shown that the NPS researchers, legislators, and policymakers are lagging behind, whereas terrorists possess an advanced power score.

The analysis of the basis of the authority of e-markets on the darknet showed comparable results on three of the renowned e-markets on the darknet; AlphaBay, Valhalla, and Hansa. Power scores of e-vendors were geographically mapped to high concentration zones in UK, US, Finland, the Netherlands, and other countries from Western Europe. Based on the random selection process, the representation of e-vendors from the Middle East appeared to be completely absent from this map; this presentation sounds in consonance with the minimal contribution of researchers from the Middle East. Furthermore, all exceptional e-vendors trading in the Middle East were found to be originally either shipping from or trading in Europe.

\section{Competing Interests Statement}

The authors have no conflict of interest to be declared.

\section{Source of Funding}

This study has been entirely self-funded. 


\section{References}

Agichtein, E., Lawrence, S., \& Gravano, L. (2001, April). Learning search engine specific query transformations for question answering. In Proceedings of the 10th international conference on World Wide Web (pp. 169-178). ACM. https://doi.org/10.1145/371920.371976

Al-Imam, A. (2017). Could Hallucinogens Induce Permanent Pupillary Changes in (Ab) users? A Case Report from New Zealand. Case Reports in Neurological Medicine, 2017. https://doi.org/10.1155/2017/2503762

AL - Imam, A., Santacroce, R., Roman - Urrestarazu, A., Chilcott, R., Bersani, G., Martinotti, G., \& Corazza, O. (2017). Captagon: use and trade in the Middle East. Human Psychopharmacology: Clinical and Experimental, $32(3)$.

Al-Imam, A., Simonato, A. P., \& Corazza, O. (2016). Haloperidol, an old antipsychotic with potential use by NPS users in Iraq. Research and Advances in Psychiatry, 3(3), 81-84. Retrieved from https://www.rapjournal.eu/materiale_cic/948_3_3/8031_haloperidol/article.htm

Bourdieu, P. (1994). Structures, habitus, power: Basis for a theory of symbolic power. Culture/power/history: A reader in contemporary social theory, 155, 199.

Broséus, J., Rhumorbarbe, D., Mireault, C., Ouellette, V., Crispino, F., \& Décary-Hétu, D. (2016). Studying illicit drug trafficking on Darknet markets: structure and organisation from a Canadian perspective. Forensic science international, 264, 7-14. https://doi.org/10.1016/j.forsciint.2016.02.045

Burgess, J., \& Green, J. (2013). YouTube: Online video and participatory culture. John Wiley \& Sons.

Campbell, D. T. (1975). On the conflicts between biological and social evolution and between psychology and moral tradition. American psychologist, 30(12), 1103. https://doi.org/10.1037/0003-066X.30.12.1103

Celestini, A., Me, G., \& Mignone, M. (2017, January). Tor Marketplaces Exploratory Data Analysis: The Drugs Case. In International Conference on Global Security, Safety, and Sustainability (pp. 218-229). Springer, Cham.

Conrad, D. (2002). Deep in the hearts of learners: Insights into the nature of online community. International Journal of E-Learning \& Distance Education, 17(1), 1-19.

Dargan, P., \& Wood, D. (Eds.). (2013). Novel psychoactive substances: classification, pharmacology and toxicology. Academic Press.

Kornbeck, J. (2013). A Guide to the World Anti-Doping Code: A Fight for the Spirit of Sport.

Ekici, B., \& Ozbay, S. (2013). Iranian methamphetamine and Turkey: an emerging transnational threat. Trends in organized crime, 16(3), 286-305. https://doi.org/10.1007/s12117-013-9204-6

EMCDDA, I. (2013). European Drug Report 2016: Trends and Developments.

Fayyad, U., Piatetsky-Shapiro, G., \& Smyth, P. (1996). From data mining to knowledge discovery in databases. AI magazine, 17(3), 37.

Frey, B. S. (1999). Economics as a science of human behaviour: Towards a new social science paradigm. Springer Science \& Business Media. https://doi.org/10.1007/978-1-4615-5187-4

Ganor, B., \& Halperin Wernli, M. (2013). The infiltration of terrorist organizations into the pharmaceutical industry: Hezbollah as a case study. Studies in Conflict \& Terrorism, 36(9), 699-712. https://doi.org/10.1080/1057610X.2013.813244

Grisham, J., Barreras, C., Afarin, C., Patton, M., \& Chen, H. (2016, September). Identifying top listers in Alphabay using Latent Dirichlet Allocation. In Intelligence and Security Informatics (ISI), 2016 IEEE Conference on (pp. 219-219). IEEE. https://doi.org/10.1109/ISI.2016.7745477

Helander, A., Beck, O., Hägerkvist, R., \& Hultén, P. (2013). Identification of novel psychoactive drug use in Sweden based on laboratory analysis-initial experiences from the STRIDA project. Scandinavian journal of clinical and laboratory investigation, 73(5), 400-406. https://doi.org/10.3109/00365513.2013.793817

Jelen, B., \& Alexander, M. (2006). Pivot Table Data Crunching for Microsoft (R) Office Excel (R) 2007 (Business Solutions). Que Corp.

Katz, D., \& Kahn, R. L. (1978). The social psychology of organizations (Vol. 2). New York: Wiley.

Kravitz, M., \& Nichols, W. (2016). A Bitter Pill to Swallow: Connections between Captagon, Syria, and the Gulf. Journal of International Affairs, 69(2), 31. 
Mackey, T. K., \& Liang, B. A. (2013). Improving global health governance to combat counterfeit medicines: A proposal for a UNODC-WHO-Interpol trilateral mechanism. BMC medicine, 11(1), 233. https://doi.org/10.1186/1741-7015-11-233

Martín-Martín, A., Ordu-a-Malea, E., Ayllón, J. M., \& López-Cózar, E. D. (2016). The counting house: measuring those who count. Presence of Bibliometrics, Scientometrics, Informetrics, Webometrics and Altmetrics in the Google Scholar Citations. ResearcherID, ResearchGate, Mendeley \& Twitter. arXiv preprint arXiv: 1602.02412 .

Mayer, J. R. (2009). Any person... a pamphleteer": Internet Anonymity in the Age of Web 2.0. Undergraduate Senior Thesis, Princeton University.

Moore, K., Dargan, P. I., Wood, D. M., \& Measham, F. (2013). Do novel psychoactive substances displace established club drugs, supplement them or act as drugs of initiation? The relationship between mephedrone, ecstasy and cocaine. European addiction research, 19(5), 276-282. https://doi.org/10.1159/000346678

Morrow, J. D., \& Morrow, J. D. (1994). Game theory for political scientists (No. 30: 519.83). Princeton University Press,

O'leary, Z. (2004). The essential guide to doing research. Sage.

Phelps, A., \& Watt, A. (2014). I shop online-recreationally! Internet anonymity and Silk Road enabling drug use in Australia. Digital Investigation, 11(4), 261-272. https://doi.org/10.1016/j.diin.2014.08.001

Pildes, R. H. (2001). Is Voting-Rights Law Now at War with Itself--Social Science and Voting Rights in the 2000s. NCL Rev., 80, 1517.

Shubik, M. (1984). Game theory in the social sciences (p. 22). Cambridge: MIT press.

Spekman, R. E. (1979). Influence and information: An exploratory investigation of the boundary role person's basis of power. Academy of Management Journal, 22(1), 104-117. https://doi.org/10.2307/255482

University of Michigan. Influencing People. Retrieved from https://www.coursera.org/learn/influencing-people (accessed 04 March 2017)

US National Library of Medicine National Institutes of Health. Retrieved 3 March, 2017, from https://www.ncbi.nlm.nih.gov/pubmed

Van Hout, M. C., \& Bingham, T. (2014). Responsible vendors, intelligent consumers: Silk Road, the online revolution in drug trading. International Journal of Drug Policy, 25(2), 183-189. https://doi.org/10.1016/j.drugpo.2013.10.009

Ward, R. H., \& Mabrey, D. J. (2013). Organized Crime in Asia and the Middle East. Handbook of Transnational Crime and Justice, 443.

Wehinger, F. (2011, September). The Dark Net: Self-regulation dynamics of illegal online markets for identities and related services. In Intelligence and Security Informatics Conference (EISIC), 2011 European (pp. 209-213). IEEE.

Wood, D. M., Hunter, L., Measham, F., \& Dargan, P. I. (2012). Limited use of novel psychoactive substances in South London nightclubs. QJM: An International Journal of Medicine, 105(10), 959-964. https://doi.org/10.1093/qjmed/hcs107

Wrong, D. (2017). Power: Its forms, bases and uses. Routledge.

\section{Copyrights}

Copyright for this article is retained by the author(s), with first publication rights granted to the journal.

This is an open-access article distributed under the terms and conditions of the Creative Commons Attribution license (http://creativecommons.org/licenses/by/4.0/). 